\title{
Cyanobacteria: Pioneers of Planet Earth
}

\author{
S. A. Kulasooriya \\ Emeritus Professor of Botany, University of Peradeniya, Peradeniya, Sri Lanka and Visiting Professor \\ Institute of Fundamental Studies, Kandy, Sri Lanka.
}

\begin{abstract}
Cyanobacteria are among the earliest of inhabitants of Planet Earth and their existence can be traced back to 3.8 billion years. Their oxygenic photosynthesis led to the gradual conversion of the Earth's atmosphere from an anaerobic to an aerobic one. This change enabled the advent of aerobic organisms that eventually underwent rapid evolution and became the dominant, highly diverse members of the current global biodiversity. Cyanobacteria are ubiquitous in their distribution and are found in all the latitudes from Arctic and Anatarctic regions to the Tropical deserts perhaps reflecting their pioneering habitation of the primitive earth. They are also unique in their ability to simultaneously perform oxygenic photosynthesis and oxygen labile nitrogen fixation. Through these processes they make significant contributions to the Carbon and Nitrogen bio-geochemical cycles, particularly in the deep oceans. The ability of these organisms to fix $\mathrm{N}_{2}$ either independently or in symbiosis with other organisms not only contributes to natural ecosystems but is applied in certain countries particularly for rice cultivation. Their ability to grow in highly polluted environments is also used in the treatment of sewage and industrial effluents. Cyanobacteria are the most efficient among all living organisms in the harvesting of solar energy and are currently looked at as highly attractive candidates for biofuel production. A few species are being used for the production of highly nutritive food supplements. On the negative side, some cyanobacteria form massive growths called 'blooms' in water bodies and many of them produce toxins harmful to fish, digastric animals and are suspected to be responsible for certain human ailments. Having reviewed most of these aspects of cyanobacteria, it is concluded that knowledge on these little known organisms would be invaluable not only for students, scientists and environmentalists but also for industrialists and policy makers.
\end{abstract}

Key words: cyanobacteria, blue-green algae, algal toxins, biofertilizers, biofuels

\section{INTRODUCTION}

Cyanobacteria, also known as blue-green algae include a highly diverse group of prokaryotic microorganisms exhibiting oxygenic photosynthesis. Oxygen released by this process gradually changed the original reducing atmosphere of the primitive earth to an oxidizing one (Olsen, 2006) triggering off a dramatic evolution of global biodiversity. The chloroplasts of eukaryotic algae and higher plants have originated from endosymbiotic relationships with cyanobacteria (Martin and Kowallik, 1999 and Raven and Allen, 2003) and this event in the early evolution of life has stimulated the advent of oxygen tolerant flora and fauna capable of aerobic respiration, a highly efficient mechanism of energy utilization. The rapid development of such organisms resulted in the predominance of oxygenic and aerobic species diversity on earth.

Cyanobacteria are genetically highly diverse; they occupy a broad range of habitats across all latitudes perhaps demonstrating the abilities of their pioneering ancestors as the earliest inhabitants of Earth. They are not only widespread in freshwater, marine and terrestrial ecosystems but also found in extreme habitats such as hot springs, hypersaline localities, freezing environments and arid deserts (Fogg et al., 1973). They often live in association with other organisms forming microbial mats, biofilms and benthic communities and such associations are the predominant and sometimes the only life forms found in certain extreme habitats. The fossilized stromatolites believed to have been formed some 3.4 billion years ago (bya) are also microbial communities with cyanobacteria as their autotrophic partners.

Diverse species having different ecological demands exhibit differential adaptations to the conditions at their source locality. The massive communities of Prochlorococcus in the oligotrophic deep oceans that live in close association with cyanophages enabling rapid lateral transfer of genomic material opens up

Author's email: ananda@kulasooriya.com 
new vistas on biological adaptation and evolution (Johnson et al., 2006). The endolithic Chroococcidiopsis living as the only inhabitant in the extremely inhospitable habitat of the arid Atacama Desert provides a new tool for Astrobiology (Friedmann, 1982 and Wierzchos et al., 2006).

Sequencing of $16 \mathrm{~S}$ rRNA while confirming the existence of several morphologically uniform and well-defined traditional genera, has also placed similar morphotypes in distant positions in phylogenetic trees. Molecular data therefore provide basic criteria for cyanobacterial taxonomy, but to construct a comprehensive phylogenetic system of cyanobacteria a combination with knowledge on their morphology, physiology and biochemistry is essential (Komarek, 2006).

The ability of certain cyanobacteria to fix atmospheric nitrogen make them unique in their ability to independently secure their carbon and nitrogen requirements (Kulasooriya, 2008). Some of these organisms and symbiotic systems like Azolla are used as biofertilizers, particularly in rice production (Venkataraman, 1972 and Azolla Utilization, 1987). They are also applied in oxidation ponds and sewage and sludge treatment plants (Lincoln et al., 1996). Recently a few species have been investigated for biofuel production because their ability to convert solar energy has been found to be the most efficient among all living organisms. Furthermore, their simple genomic structure has enabled the production of biofuel secreting strains through genetic engineering (Lane, 2010). Certain cyanobacteria form blooms in eutrophied water bodies and most of such bloom forming strains produce cyanotoxins that are harmful and sometimes lethal to animals and humans (Carmichael, 1994 and Carmichael et al., 2001). A few species are utilized for the production of highly nutritious food supplements (Kulshreshtha et al., 2008)

This paper reviews the current information on these aspects of cyanobacteria, the roles they may have played in the origin and early evolution of life on earth and their current impacts on global biodiversity.

\section{Role in the oxygenation of the primitive earth's atmosphere}

The Planet Earth is believed to have cooled down, solidified and formed oceans and terrestrial habitats some 4.8 to 4.5 (bya). During the next billion years chemical or abiotic evolutionary processes in the primordial soup of the oceans are believed to have given rise to primitive entities capable of self replication.
Various scientists have reported on these processes which have resulted in the formation of amino acids (monomers and proteinoid polymers) that integrated to form aggregates such as protobionts and microspheres with semipermeable membranes. Ribose-nucleic acid (RNA) is believed to have been the original hereditary molecule that grew, split and was passed onto the progeny. These have given rise to the earliest life forms on earth which are believed to be prokaryotic organisms, today represented by the Archea, Eubacteria and the Cyanobacteria. Citing evidence from the Isua super-crustal belt in Western Greenland and similar formations in Akilia Island, Mojzsis et al. (1996) proposed life to have existed 3.8 bya. They have also estimated the time that would be taken for a $100 \mathrm{Kbp}$ genome of a primitive heterotroph to develop onto a $7500 \mathrm{Kbp}$ gene of a filamentous cyanobacterium to be 7 million years.

It is most likely that the original cells were heterotrophic utilizing plenty of organic molecules available in the primordial soup together with those produced by other cells. As these food supplies gradually became limiting some of the cells would have developed strategies to use the readily available solar energy by anaerobic photosynthesis. These archaic processes are still retained by a few pigmented bacterial species like Chlorobium and Rhodospirillum which utilizes energy from the sun to reduce $\mathrm{CO}_{2}$ and form organic compounds deriving electrons from substrates such as $\mathrm{H}_{2} \mathrm{~S}$ and FeS exhibiting non-oxygenic photosynthesis.

In a comprehensive mini review Olson (2006) has presented possible pathways on the early evolution of photosynthesis primarily based upon fossil evidence during the Archeon Era. According to him the earliest reductant for $\mathrm{CO}_{2}$ fixation (even by primitive cyanobacteria) would have been $\mathrm{H}_{2}$ some 3.8 bya. Fossilized filamentous mats found in the Buck Reef Cherts of South Africa and Evaporites, Stromatolites and micro-fossils observed in the Warrawoona Megasequence in Australia have been attributed to the $\mathrm{H}_{2} \mathrm{~S}$ driven photosynthesis between 3.5 to 3.4 bya and subsequently Proteobacteria and Protocyanobacteria have utilized $\mathrm{Fe}^{2+}$ ions as reductants around 3.0 bya. Evidence of retention of such archaic processes can be observed in certain present day species of cyanobacteria which exhibit light driven $\mathrm{CO}_{2}$ fixation through cyclic photophosphorylation under anaerobic conditions using electron donors such as $\mathrm{H}_{2} \mathrm{~S}$, thiosulphate, or even molecular $\mathrm{H}_{2}$. Citing evidence from microfossils, stromatolites and 
chemical biomarkers Olson (2006) suggested that cyanobacteria containing chlorophyll-a capable of $\mathrm{O}_{2}$ evolving photosynthesis appeared around 2.8 bya, but this process did not have a significant impact on the composition of the atmospheric gases for another 5 million years. The $\mathrm{O}_{2}$ released to the atmosphere became bound to limestone, iron and other minerals as evidenced from the iron-oxide rich geologic strata observed from those periods. It is also believed that such oxidative reactions of minerals contributed to the 'greening of oceans'. Once most of the minerals got oxidized free $\mathrm{O}_{2}$ gradually began to accumulate in the atmosphere. Intense solar rays bombarding the earth converted some of the $\mathrm{O}_{2}$ to $\mathrm{O}_{3}$ which collected in the upper part of the atmosphere to build up the ozone layer that absorbs the mutagenic UV rays and protects all life forms from unsustainable levels of mutation. Such a build up of a protective $\mathrm{O}_{3}$ layer would also have enabled the evolution and migration of life forms from the oceans to land.

Towards the end of the Archaeozoic era and beginning of the Proterozoic era the earth began to cool and this led to the reduction of the major greenhouse gases of the atmosphere e.g. water vapour, $\mathrm{CO}_{2}$ and methane. This cooling also reduced the hygrometric capacity of air and water vapour condensed resulting in continuous torrential rain. These changes of the physical environment led to the proliferation of cyanobacteria in the marine phytoplankton which fixed and stored part of the carbon in the sea and contributed to the reduction of $\mathrm{CO}_{2}$ in the atmosphere. Release of $\mathrm{O}_{2}$ to the atmosphere due to oxygenic photosynthesis by cyanobacteria would also have contributed to the reduction of atmospheric methane through oxidation.

Meanwhile the chloroplasts that are today so common in eukaryotic algae and green plants evolved through processes of endosymbioses between cyanobacterial and heterotrophic eukaryotic ancestors. This endosymbiotic hypothesis was originally put forward by Mereschkowsky (1905). Though originally taken with skepticism subsequent electron microscopic, biochemical and molecular biological studies gave credence to this hypothesis and later Martin \& Kowallik (1999) translated this paper into English and provided evidence in support of it by molecular analysis of the chloroplast genome of Arabidopsis thaliana and comparing it with those of Nostoc punctiforme, Prochlorococcus marinus and Synechocystis sp. PCC 6803 (Martin et al., 2002). Raven and Allen (2003) confirmed these evidences and stated that the complete genome sequences of cyanobacteria and of the higher plant Arabidopsis thaliana leave no doubt that the green plant chloroplast originated through endosymbiosis with a cyanobacterium.

The oxygenic photosynthesis of cyanobacteria and chloroplast containing eukaryotes would have accelerated the oxygenation of the atmosphere and this would have had significant impacts on the existing life forms of that time. Oxygen would have been toxic to most of the primitive organisms which were predominantly anaerobic and a large number of them would have died in what was called the 'oxygen catastrophe'. As this process of oxygenation had been very slow and gradual through several millions of years, it enabled the evolution of resistant forms some of which even developed mechanisms to utilize $\mathrm{O}_{2}$ to secure energy from food through aerobic respiration. This metabolic process was far more efficient than the anaerobic processes of fermentation and the aerobes on earth developed at a dramatic pace driving the anaerobes to near extinction. Today aerobes are the predominant living forms among both flora and fauna thriving in an atmosphere containing $21 \%$ of oxygen.

\section{Distribution and associations with other organisms}

Cyanobacteria are ubiquitous in their global distribution. They occupy a broad range of habitats across all latitudes, widespread in freshwater, marine and terrestrial ecosystems, also found in extreme habitats such as hot springs, hypersaline localities, freezing environments and arid deserts. Frequently they are the pioneer invaders (often as lichens), of exposed habitats such as bare rocks, recently piled up soil or bare land after natural disasters, exposed walls and partly constructed buildings and similar substrates which offer little or no nutrients. They are also common inhabitants of polluted water bodies, drains and garbage dumps which are generally inhospitable to most other organisms. The versatile abilities of these autotrophic prokaryotes are perhaps a reflection of their pioneering ancestry which at that time dominated the inhospitable primitive earth. Initial colonization of habitats by cyanobacteria if left undisturbed has the potential to develop through progressive autotrophic successions to reach even the final stage of a climax forest under favorable environmental conditions. Such important roles played by these simple prokaryotes justify referring to them as Pioneers of Planet Earth.

Among the planktonic cyanobacteria, the ocean dwelling Prochlorococcus marinus 
occupies a unique position. Reported as the tiniest photosynthetic organisms and the most populous autotrophic prokaryotes in the oceans, they are found among the phytoplankton of the oligotrophic deep ocean habitats in dense populations sometimes around $10^{5}$ cells per ml of water. The vast extents of these populations in the oligotrophic deep oceans make a significant contribution to primary production and Csequestration that ameliorates global warming. Research studies led by Professor Sally W. Chisholm of the Massachusetts Institute of Technology, Boston, USA, have shown the important role played by the massive populations of these minute organisms in carbon sequestration in the vast expanses of the deep open ocean ecosystems. When we realize that over $70 \%$ of the earth's surface is covered by oceans it is easy to comprehend the significance of the contribution made by them to global Csequestration. Another astounding finding of the Massachusetts research team is the close association Prochlorococcus cells are having with numerous viruses that facilitate rapid lateral gene transfers among them. With these new findings they were able to get a clear picture of gene diversity and gene flow among these organisms and postulate that such lateral gene transfers endow upon them an intrinsic ability to rapidly adapt to environmental variables such as temperature, predators, light and nutrient changes which these organisms constantly encounter in the deep ocean ecosystems. The team's studies have shown that closely related Prochlorococcus strains display an array of physiological differences regulated by the genetic diversity of the constituent cells that provide an extraordinary stability to the overall community which internally adjusts itself to ever changing environmental conditions. These novel observations perhaps warrant the introduction of new terminology to such ecosystems. What is seen here are homogenous populations of Prochlorococcus marinus that are "heterogenomic". This dynamic heterogenomicity due to the continuous lateral gene transfer through closely associated viral vectors enable the homogenous cyanobacterial community to sustain itself in the ever changing environment of the deep ocean. Johnson et al. (2006) have categorized these heterogenomic groups as ecotypes and presented a comprehensive report on their niche distribution in ocean scale environmental gradients. Populations of Procholorococcus have been categorized into two broad groups. The High light tolerant group found on the surface of the Equatorial Pacific, down to $5 \mathrm{~m}$ in the
Mediterranean Sea, $50 \mathrm{~m}$ in the Arabian Sea, 35 $\mathrm{m}$ in the Gulf Stream and $90 \mathrm{~m}$ in the Sargasso Sea. The Low light tolerant group was observed down to $10 \mathrm{~m}$ in the North Atlantic, $83 \mathrm{~m}$ in the Equatorial Pacific, $120 \mathrm{~m}$ in the Sargasso sea and $135 \mathrm{~m}$ in the Gulf Stream. Quoting the works of Sally W. Chisholm of the MIT and Robert J. Olsen of the Woods Hole Oceanographic Institute, Nadis (2003) compares this tiny cyanobacterium to the archaic ancestors that originally developed oxygenic photosynthesis on Planet Earth and claims that they account for $50 \%$ of the total oceanic photosynthesis. Prochlorococcus is also unique among all cyanobacteria as the only genus to possess chlorophyll-b in addition to chlorophylla, resembling green algae. In fact this feature led to some debate over its taxonomic position, but all the prokaryotic features that it shares with other cyanobacteria have eventually kept it within this taxonomic group.

Another deep ocean dwelling cyanobacterium of ecological importance is Trichosdesmium, a filamentous nonheterocystous cyanobacterium which fixes atmospheric $\mathrm{N}_{2}$. How this organism has reconciled the $\mathrm{O}_{2}$ sensitive $\mathrm{N}_{2}$-fixation while carrying out oxygenic photosynthesis is still an enigma and this will be discussed later under the section on $\mathrm{N}_{2}$-fixation in cyanobacteria. Marine plankton species of cyanobacteria are not as common as freshwater species but Trichodesmium is arguably one of the commonest among them. T.erythraenum is more frequently encountered than other species like T.theibautii, T.hilderbrandi and T.rubescens. Drouet (1968) in his revision of the Family Oscillatoriaceae has grouped all these species as Oscillatoria erythraea but this did not receive universal acceptance. Trichodesmium exists in nature as bundles of filaments visible to the naked eye (Fig. 1). Usually this cynaobacterium is red in colour due to the high content of the accessory red pigment phyco-erythrin but they have been reported to have a range of colours from grey through yellow, green, and purple (Fogg et al., 1973).

It is believed by some that the "Red Sea" got its name due to thick blooms of T.erythraenum that frequently formed in it. Trichodesmium occurs in tropical oceans where the surface temperature is above $25^{\circ} \mathrm{C}$ and salinity near $3.5 \%$. It normally occurs as long windrows from a few feet to several miles in length. Wood (1965) has reported a massive bloom of nearly $52,000 \mathrm{~km}^{2}$ (almost $80 \%$ of the area of Sri Lanka). Carpenter and Romans (1991) present Trichodesmium as the most important primary 
producer in the North Atlantic Ocean (ca 165 $\mathrm{mgC} / \mathrm{m}^{2} /$ day) which also introduces the largest fraction of new nitrogen to the euphotic zone through fixation (ca $30 \mathrm{mgN} / \mathrm{m}^{2} /$ day). Capone et al. (1997) confirmed this report and illustrates in a map its global distribution in all the major oceans along the tropical belt showing its extension to the sub-tropical waters just above and just below the latitudes of $26.5^{\circ} \mathrm{N}$ and $26.5^{\circ} \mathrm{S}$ respectively. It is however claimed that its activities are confined to water temperatures above $20^{\circ} \mathrm{C}$. Karl et al. (1997) presenting results of seven years of time series observations in the North Pacific Ocean Gyre, claimed that $\mathrm{N}_{2}$ fixation by cyanobacteria accounted for half of the new production and demanded a reassessment of previous bio-geochemical nutrient cycling budgets of one of the world's largest biomes.

Another marine planktic cyanobacterium is Richelia intracellularis which lives as an endosymbiont within some large diatoms that are frequently encountered among the phytoplankton of the oligotrophic oceans (Carpenter and Romans, 1991). Although not as common as eukaryotic algae, cyanobacteria are found in the marine intertidal and littoral ecosystems, the common species being Lyngbya majuscula, Microcoleus ethnoplasts, (a common mat former), Spirulina sp. (a highly nutritious cyanobacterium) and several species of Oscillatoria. They are also found in association with marine coralline algae and marine lime stones e.g. Hyella stella and Scytonema endolithicum.

Nevertheless, the greatest abundance and diversity of cyanobacteria are encountered in freshwaters where they are far more common than their marine counterparts. Several unicellular, colonial and filamentous species have been recorded both as plankton, and benthic micro flora. They are invariably present together with other photosynthetic organisms in mesotrophic waters, the common genera being Microcystis, Synechococcus, Anacystis, Gloeocapsa, Agmenellum (syn. Merismopedia) as unicellular and colonial types and Oscillatoria, Lyngbya, Spirulina, Ananbaena, Aphanizomenon, Nostoc, Cylindrospermopsis, Planktothrix, Calothrix, Rivularia and Gleoetrichia as filamentous types. With pollution and nutrient loading such water bodies become eutrophic and very often certain cyanobacteria that prefer such environments outgrow their counterparts producing explosive growths to form 'algal blooms'. The common bloom forming genera are Microcystis, Cylindrospermopsis, Anabaena and Aphanizomenon. Some times these blooms could be massive. The author once had the experience of measuring such a bloom in 1991 that formed adjacent to the Kotmale Hydro-Power Reservoir Dam which was $1.5 \mathrm{~m}$ deep and extended to more than $2000 \mathrm{~m}^{2}$ (unpublished personal observation). They foul the water and most of them produce 'algal toxins' that are often lethal to fish and digastric mammals, cause diseases, irritations, allergies and also contribute to liver and kidney ailments among humans. (A more detailed analysis is included in the section on 'toxigenic cyanobacteria'). In the aquatic ecosystems cyanobacteria play a crucial role as oxygenic primary producers as well as nitrogen fixers.

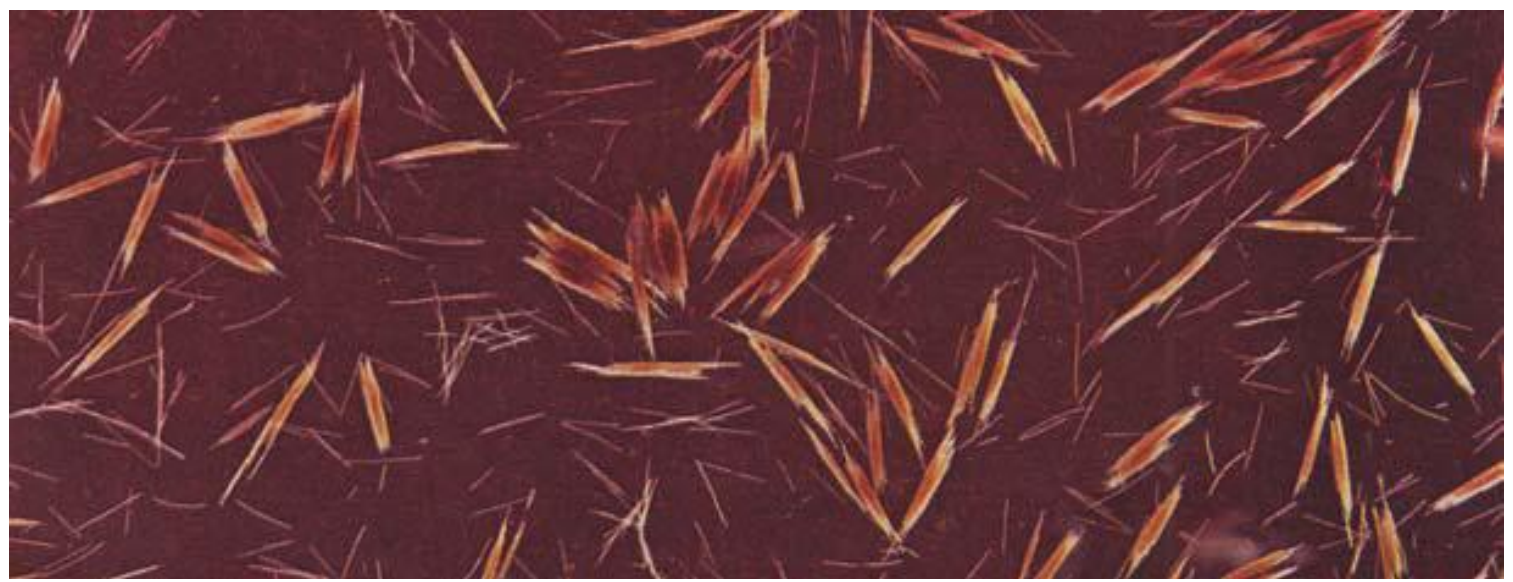

Figure 1. Colonies of Trichodesmium erythraenum. (Source: Reproduced from Fogg et al.,1973) 
Their environmental sensitivity and short life cycles resulting in rapid species turnover are helpful to use them as biological indicators in environmental assessment studies. For example $\mathrm{N}_{2}$ fixing cyanobacteria have been used to understand the water quality especially high turbidity, low N:P ratio, metal toxicity and nitrogen limitations in the environment. The photosynthetic pigments and resting stages they produce to survive harsh environmental conditions have sometimes remained even for thousands of years. Such remains provide reliable historical information when monitoring data are not available. Recent developments in environmental science and biostatistics help quantify ecological optima and tolerances of such indicator organisms, enable the assessment of past environmental conditions and predict future global scenarios such as climate change (Yatigammana, 2004).

Free living cyanobacteria are found in all terrestrial habitats but are frequently observed in moist environments. They produce luxuriant growth in wetlands, marshy lands and rice fields. Common terrestrial genera are Aphanocapsa, Gloeocapsa, Merismopedia, Eucapsis as unicellular and colonial types, Oscillatoria, Lyngbya, Microcoleus, Spirulina as undifferentiated filamentous types, Nostoc, Anabaena, Cylindrospermum, Calothrix, Scytonema, Tolypothrix as differentiated filamentous forms and Mastigocladus, Fischerella, Westiella, Westiellopsis and Stigonema as true branched, differentiated filaments This range of morphological diversity extending from simple unicellular forms to multicellular, heterotrichous, true branched filamentous morphotypes bestow upon the cyanobacteria a unique position as the most complex organisms among all the Prokaryota.

Cyanobacteria either by themselves or in symbiosis with fungi as lichens are often the pioneering colonizers of bare soils, rocks and other exposed surfaces with little or no nutrients indicating their ability to adapt to inhospitable environments. Such abilities have sometimes being utilized by soil microbiologists as in the reclamation of alkaline 'Usar Soils' of India by bio-fertilization with Aulosira fertilissima (Singh, 1961).

The adaptability of cyanobacteria to extreme environments is exemplified by certain species being extremophiles i.e. inhabitants of extreme habitats. They are found in freezing habitats as "green snow", in glaciers and as endolithic members in the sub surface of Arctic and Antartic rocks Friedmann (1982). Friedmann et al. (1988) reported cyanobacteria and lichens as cryptoendolithic organisms in the frigid deserts of the Antarctic dry valleys where no other life forms are visible on the surface. They live in between crystals of porous rocks and their activities contribute to the weathering of these rocks. The common genus observed in these freezing habitats is Chroococcidiopsis, a unicellular cyanobacterium belonging to the Order Chroococcales. In these habitats temperatures are normally around $-20^{\circ} \mathrm{C}$ and even in the warmest periods do not go over $0^{\circ} \mathrm{C}$. On the other hand the extremophile Chroococcidiopsis has also been reported as the only life form found in the hyper arid core of the Atacama Desert in South America living as an endolithic organism beneath halite rocks (Weirzchos et al., 2006). Cyanobacteria are also found endolithically in large columnar calcified structures called stromatolites in the Australian tidal flats. Stromatolites are extremely slow growing structures and some of the fossilized stromatolites of Australia believed to be 3.4 billion years of age depict remains of endolithic fossil cyanobacteria. The ability of Chroococcidiopsis to grow in such extreme habitats has prompted the NASA scientist E. Imre Friedmann to suggest it as a candidate of choice to be used in its Astrobiology Programs to introduce life to the Red Planet Mars.

Cyanobacteria often live in association with other organisms forming microbial mats, biofilms and benthic communities and such associations are the predominant and sometimes the only life forms found in certain extreme habitats like hot springs. Certain species like Rickelia intracellularis lives as endosymbionts in large diatoms. Cyanobacteria are also endosymbiotic in fungi (lichens), bryophytes (Anthoceros), pteridophytes (Azolla), cycads (coralloid roots), angiosperms (Gunnera) and certain marine sponges and corals.

\section{Morphology, taxonomy and molecular biology}

Cyanobacteria exhibit the most diverse and complex morphology among all prokaryotic groups, perhaps indicating that they would have been the dominant life forms at some period of the early earth. External gross appearance under aquatic and/or moist conditions is often gelatinous, slimy and occasionally filamentous clusters, with colours ranging from dark green, blue-green, yellow, brown to black, and rarely red (Fig. 2).

This variable colour range is primarily due to their photosynthetic pigments consisting of chlorophyll-a (which all of them possess) together with different concentrations of the 
accessory phyco-biliprotein pigments, phycocyanin (blue) and phycoerythrin (red). The final external colour of a specimen is largely dependent upon the concentrations of these pigments. Characteristically all cyanobacteria have thin or thick gelatinous sheaths outside their cell walls, their thickness and sometimes their colour contribute to the final appearance of the organism.

Although cyanobacteria perform oxygenic photosynthesis just like eukaryotic green algae and higher plants, they do not store food in the form of starch. Their principal storage product is cyanophycean starch and glycogen together with specialized intracellular storage compounds like lipids, protein containing cyanophycean granules and polyphosphate bodies. Some cyanobacteria particularly the plankton species produce intracellular 'gas vacoules'. These are quite different from typical membrane bound vacoules of eukaryotic cells and are actually groups of gas filled vesicles that collapse under sudden shock and pressure. These vesicles enhance buoyancy and this helps such species to move up and down a water column and occupy a depth that provides the best micro-niche in an aquatic environment.

The somatic diversity of cyanobacteria extends from unicellular forms, colonial assemblages, unbranched filaments to filaments with false and true branching. As these organisms do not show sexual reproduction their taxonomy has been entirely based upon morphology until the mid $20^{\text {th }}$ century (Geitler, 1932, Fritsch, 1942 and Desikachary, 1959). A sample of a brief classification based on morphological diversity is given below:

Group: Algae (Eukaryotic)

Division: Chlorophyta (Green algae)

Class Cyanophyceae or Myxophyceae (BlueGreen algae)

Order Chroococcales - unicellular and colonial members.

Unicells e.g. Anacystis, Synechococcus and Chroococcus,

Loose colonies e.g. Microcystis,

Compact colonies e.g. Gloeocapsa,

Colonies of definite shape e.g. flat plates Merismopedia (syn. Agmenellum) and cuboidal colonies e.g. Eucapsis.

Order Chaemosiphonales - A small group that grows attached and produces a type of asexual exospores e.g. Chaemosiphon and Dermocarpa.

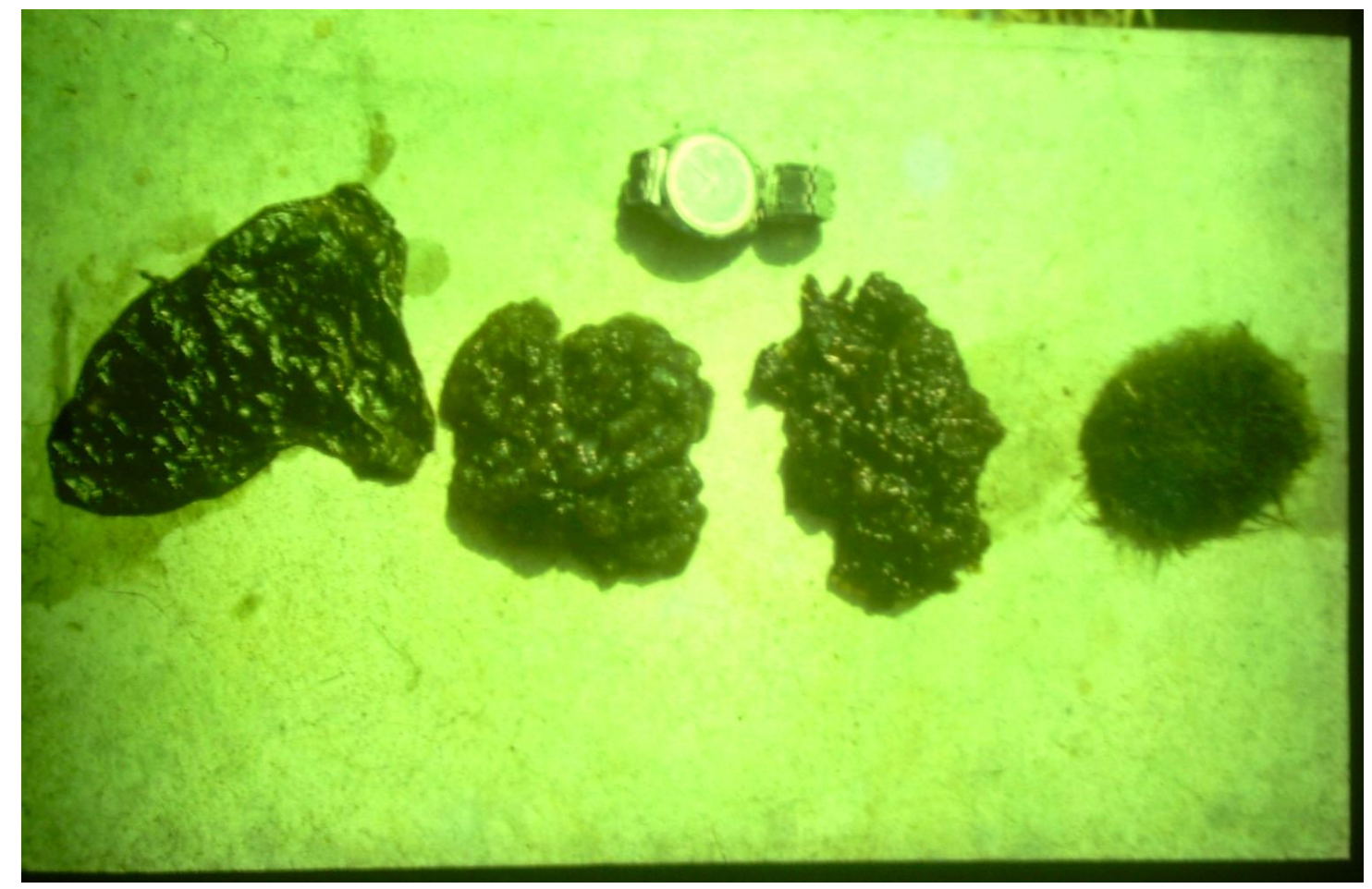

Figure 2. External appearance of some cyanobacteria collected from paddy fields in Sri Lanka. 
Order: Oscillatoriales - Unbranched, undifferentiated filaments e.g. Oscillatoria and Spirulina (thin sheaths), Lyngbya (thick sheath), Microcoleus (several trichomes within a common sheath).

Order Nostocales - Unbranched filaments exhibiting cell differentiation into vegetative cells, heterocysts and akinetes (spores).

Family Nostocaceae: Simple filaments e.g. Nostoc, Anabaena, Cylindrospermum (terminal heterocysts with large basal akinete).

Family Rivulariaceae: Whip-like tapering filaments e.g Calothrix (non-colonial with or without spores), and colonial Rivularia (non sporing) and Gloeotrichia (sporing).

Family Scytonemataceae: Filaments with false branching e.g. Tolypothrix (more single branches) and Scytonema (more double branches).

Order Stigonematales - Members having true branches.

Family Nostochopsidaceae: Members do not exhibit heterotrichous habit e.g. Nostochopsis.

Family Stigonemataceae: Those showing heterotrichous thalli with prostrate and erect systems e.g.:

Mastigocladus both prostrate and erect systems uniseriate.

Frischerella prostrate system multiseriate and erect system uniseriate.

Stigonema climax thallus development with both systems multiseriate.

With the advent of electron microscopy and molecular biology these simple classification systems had to be reviewed and revised. Revisions of different groups have been reported by Drouet \& Daily (1956) and Drouet (1968, 1973, 1977). The realization of the prokaryotic cell structure of the 'blue-green algae' warranted a radical change in their taxonomy and it was proposed by a leading team of blue-green algologists (at that time) to place the nomenclature of these organisms under the International Code of Nomenclature of Bacteria (Stanier et al., 1978), but this proposal has been questioned (Komarek, 2006). Rippka et al. (1979) revised the generic assignments of a number of pure cultures of cyanobacteria. Application of modern molecular biological techniques has brought about radical changes in the taxonomy of cyanobacteria. Sequencing of 16S rRNA while confirming the existence of several morphologically uniform and welldefined traditional genera, has also placed similar morphotypes in distant positions in phylogenetic trees. Molecular data therefore, provide basic criteria for cyanobacterial taxonomy, but to construct a comprehensive phylogenetic system of cyanobacteria a combination with knowledge on their morphology, physiology, biochemistry and ecology is essential. For a comprehensive review of combined molecular and phenotype taxonomic evaluations of cyanobacteria readers are referred to Komarek (2006). In this review he has emphasized the necessity to adopt a 'polyphasic' approach combining the knowledge gained through modern ecological, ultra structural and molecular methods supported by the cultivation of numerous cyanobacterial morphotypes. It is stated that while molecular data provide basic criteria for cyanobacterial taxonomy, a correct phylogenetic system cannot be constructed without combining the data from previous 150 years of studies on cyanobacterial diversity. The limitations of using 'type strains' from standard culture collections for systematic and nomenclatural purposes, are also highlighted in this review.

\section{Nitrogen fixation and its applications}

The ability of certain cyanobacteria to fix atmospheric nitrogen make them unique in their being autotrophic in both carbon and nitrogen nutrition. It is also intriguing to find how these prokaryotic organisms (without intracellular organelles) simultaneously perform two incompatible processes of oxygen evolving photosynthesis and oxygen sensitive nitrogen fixation.

Phylogenetic studies have indicated that all nitrogenases have been derived from a common prokaryotic ancestral group that existed prior to the oxygenation of the Earth's atmosphere (Berman-Frank et al., 2003). In this anoxic atmosphere having a predominance of $\mathrm{CH}_{4}$, $\mathrm{CO}_{2}, \mathrm{~N}_{2}$, and $\mathrm{NH}_{3}$, ultra-violet radiation would have dissociated $\mathrm{NH}_{3}$ releasing $\mathrm{N}_{2}$. Primitive nitrogenases could have initially arisen as respiratory enzymes where $\mathrm{N}_{2}$ acted as a sink for anaerobic respiration of certain heterotrophs. The slow process of oxygenation over several millions of years primarily due to the oxygenic photosynthesis of cyanobacteria, resulted in the partial pressure of atmospheric oxygen to increase from $4 \times 10^{-6}$ to $>0.03 \%$. This oxygenation was inimical to $\mathrm{N}_{2}$ fixation and all organisms had to adopt various methods to protect their nitrogenase enzyme from damage by $\mathrm{O}_{2}$. Gallon et al. (1991) has extensively discussed these mechanisms as behavioural adaptations, physical barriers, physiological and biochemical strategies and treated the 
cyanobacteria as a special group and these have been discussed by Kulasooriya (2008).

Major adaptations among cyanobacteria are structural changes among their cells. The vast majority of cyanobacteria that exhibit aerobic nitrogen fixation possess a type of specialized cell called heterocyst. Compared to vegetative cells heterocysts are generally larger in size, lighter in colour, have thicker cell walls and have thickenings called polar nodules at the points of attachment to adjacent cells. Kulasooriya et al. (1972) reported on the differentiation of heterocysts in Anabaena cylindrica and its coincidence with the restoration of nitrogenase activity. When cultured in the laboratory in media with combined nitrogen (particularly $\mathrm{NH}_{4}$ ions), the filaments did not produce heterocysts and they lost their nitrogenase activity. When such induced 'non-heterocystous' filaments were transferred to $\mathrm{N}$-free media, pro-heterocysts reformed within 24 hours. Once these proheterocysts matured into heterocysts within the next 24 hours (which could be detected by the formation of polar nodules), nitrogenase activity was restored. It was also found that the cellular $\mathrm{C}: \mathrm{N}$ ratio was critical for heterocyst formation as well as expression of nitrogenase activity. A mature heterocyst has a thick envelope that consists of an outer polysaccharide fibrous layer, a middle homogenous layer and an inner glycolipid laminated layer (Lang and Fay, 1971). This cell envelope has been shown to be critically important for nitrogen fixation and limit the ingress of $\mathrm{O}_{2}$ into the heterocysts (Murry et al., 1984 and Murry and Wolk, 1989). Isolated heterocysts showed higher levels of respiration and their absorption spectrum coincided more closely than that of the vegetative cells, with the action spectrum of nitrogenase activity of whole filaments (Fay and Walsby, 1966). Isolated heterocysts contained very little chlorophyll-a and were devoid of phycocyanin and phycoerythrin pigments which are associated with the $\mathrm{O}_{2}$ evolving photosystem-II of photosynthesis (Thomas, 1970). Using ${ }^{14} \mathrm{C}$ labeled $\mathrm{CO}_{2}$ Wolk (1970) showed that heterocysts do not fix carbon and Fay and Kulasooriya (1972) demonstrated the prevalence of reducing conditions in heterocysts by the reduction of Triphenyl Tetrazolium Chloride. Eventually Wolk and Wojciuch (1971) demonstrated photo-reduction of acetylene and (Janaki and Wolk, 1982) showed the presence of nitrogenase in isolated heterocysts. Wolk (1982) reviewed and summarized all the available evidences and concluded that the main function of the heterocyst is nitrogen fixation.
Meanwhile reports came in on the detection of nitrogenase activity in certain unicellular as well as non-heterocystous, filamentous species of cyanobacteria. The first report of a unicellular species was that of Wyatt and Silvey (1969) who demonstrated nitrogenase activity in Gloeocapsa (syn.Gloeothece and Cyanothece). These were followed by reports on other unicellular species such as Synechococcus and Aphanothece (Mitsui et al., 1986), and filamentous non-heterocystous forms like Microcoleus chnoplastes (Pearson et al., 1981) and Oscillatoria sp. (Gallon et al., 1991). In all these cases it has been found that there was a temporal separation of the two incompatible processes of oxygenic photosynthesis and oxygen sensitive nitrogen fixation along the growth cycle of these organisms. The other reported physiological and biochemical strategies adopted by these organisms have been reviewed in Kulasooriya (2008).

The most enigmatic situation was encountered with the large marine blooms of the non-heterocystous, filamentous cyanobacterium Trichodesmium erythraenum which showed very high nitrogenase activity and it was the main contributor to the nitrogen budget of the deep oceans (Karl et al., 1997). Two other species $T$. theibautii and $T$. aureum have also being identified as nitrogen fixing, non-heterocystous, marine cyanobacteria. Certain studies have demonstrated the presence of some specialized cells called diazocytes in these organisms and it has been suggested that the nitrogenase enzyme is confined to these cells (Jansen et al., 1994, Fredrickson and Bergman, 1995 \& 1997, Lin et al., 1998 and Mulholland and Capone, 2000). Nitrogen fixation in Trichodesmium peaked around midday and varied inversely with photosynthetic $\mathrm{O}_{2}$ evolution. It has also been suggested that $\mathrm{N}_{2}$ fixation and photosynthesis in Trichodesmium is regulated by circadian rhythms (Chen et al., 1998). Molecular studies on natural populations of $T$. theibautii have shown that nitrogenase is synthesized early morning and nifH mRNA is highest before dawn (Wyman et al., 1996). This enzyme remained active until noon when it reached a peak, then declined in the afternoon and got degraded during the night (Capone et al., 1990 and Zer et al., 1993). Twelve nif genes cloned and sequenced from Trichodesmium are basically similar to those of other cyanobacteria, but show a closer resemblance to 'vegetative cell nitrogenase genes' induced in Anabaena variabilis under micro-aerobic conditions. Many other non-heterocystous cyanobacteria such as species of Oscillatoria, Lyngbya, Microcoleus 
and Plectonema boryanum have been induced to fix nitrogen under micro-aerobic conditions.

Among other strategies, aggregation of unicellular and non-heterocystous cyanobacteria to form algal mats, colonies, biofilms among themselves and with other microorganisms have been reported to exhibit low levels of nitrogenase activity in marine Synechococcus and Trichodesmium and terrestrial and freshwater Oscillatoria, Lyngbya, Microcoleus and Plectonema. Physical barriers such as thick mucilaginous sheaths and capsules have enabled expression of nitrogenase activity in Gleoetheca (syn. Gloeocapsa and Cyanothece). As a biochemical protective mechanism nitrogenase activity has been shown to be regulated by ADPribosylation of the $\mathrm{Fe}$-protein (the more $\mathrm{O}_{2}$ sensitive component of the nitrogenase enzyme complex). Such adaptations originally demonstrated in photosynthetic bacteria have been found to be widespread among cyanobacteria such as Anabaena CA, Anabaena variabilis, Aphanizomenon flos-aqaue, Oscillatoria limosa, Trichodesmium, Gloeotheca and Microcoleus chthnoplasts as reviewed by Kulasooriya (2008). Continuous synthesis of nitrogenase enzyme has also been demonstrated in certain taxa like Anabaena CA, Anabaena variabilis, Anabaena flos-aquae and Gloeothece, but this strategy appears to be of limited distribution.

All these evidences support the idea that although heterocysts are specialized cells for $\mathrm{N}_{2}$ fixation in cyanobacteria the potential to fix $\mathrm{N}_{2}$ is present even in the vegetative cells but this is expressed only under reduced oxygen concentrations. These observations have important ecological implications and it is quite likely that the subterranean layers of thick mats of non-heterocystous cyanobacteria may be fixing nitrogen particularly under low light conditions or in the dark. This idea is also compatible with the evolution of the process of $\mathrm{N}_{2}$-fixation from an archaic reducing Earth's atmosphere through a micro-aerobic atmosphere to the oxygenated atmosphere of present times (Gallon et al., 1991 and Berman-Frank et al., 2003). In symbiotic associations it is always the cyanobacterial partners that fix nitrogen. They provide nitrogen to the ecosystem in which they live and often the rates of fixation by these systems are higher than those of free-living cyanobacteria, perhaps due to the additional nutrition and micro-aerobic conditions provided by the host. Occasionally cyanobacteria have been reported to be epiphytic on rice plants (Roger et al., 1981) and weeds in wetland rice fields (Kulasooriya et al.,1981a) and even endophytic in the leaf sheaths of deepwater rice (Kulasooriya et al., 1981b) and the nitrogen they fix has been shown to be available to the associated host plants (Watanabe et al.1982).

Free living nitrogen fixing cyanobacteria and the aquatic fern Azolla (which has nitrogen fixing Anabaena azollae as an endosymbiont), have been used as biofertilizers in rice cultivation. Venkataraman (1972) provides a comprehensive account of the large scale production of cyanobacterial bio-fertilizers in India. Cyanobacteia are initially isolated from rice fields, purified and screened for rapid growth and high $\mathrm{N}_{2}$-fixation. Selected isolates are then semi-mass cultured in laboratory media and these are used as inoculants for soil based outdoor mass cultures in open ponds or large trays under non-sterile conditions. A sprinkle of $P$ fertilizer, lime and pesticides are usually added to ensure uninhibited rapid growth. After sufficient growth is obtained the cultures are allowed to sun dry and the soil based algal flakes are packed and distributed among farmers to be used as bio-fertilizers. This low cost technology quite suitable for resource poor rural farmers has been successful only in a few areas in India where edaphic conditions are favourable for the growth of cyanobacteria. Reports from certain areas of Myannmar, China and Egypt have also recorded some successes. Roger and Kulasooriya (1980) reviewed most of the literature on the use of cyanobacterial biofertilizers and concluded that their $\mathrm{N}$-input potential ranged from 0 to $80 \mathrm{Kg} / \mathrm{ha} /$ season with an average of $25 \mathrm{Kg} / \mathrm{ha}$. Attempts to adopt this technology in Sri Lanka was successful only up to the stage of pot experiments and most of the cyanobacterial fertilizers added to the rice fields could not overcome consumption by the rice field micro-fauna and competition by indigenous micro-flora and failed to colonize the fields (Kulasooriya and Hirimburegama, 1989). Compared to free living cyanobacteria, the application of Azolla in rice cultivation has been more successful and widely used particularly in Vietnam, China and certain parts of Philippines. The status of this technology has been well reviewed at a workshop held in Fuzhou in Fujian Province, China and published by the International Rice Research Institute, Philippines in 1987 as 'Azolla Utilization'. Even in Sri Lanka this technology appeared to be more feasible than free living cyanobacterial biofertlizers. Azolla grew well in rice fields at Ambalantota (Fig. 3), Bombuwela, and Peradeniya and showed a potential to replace an equivalence of 55 to $85 \mathrm{KgN} / \mathrm{ha}$ of chemical $\mathrm{N}$ fertilizer (Kulasooriya et al., 1987). The major 


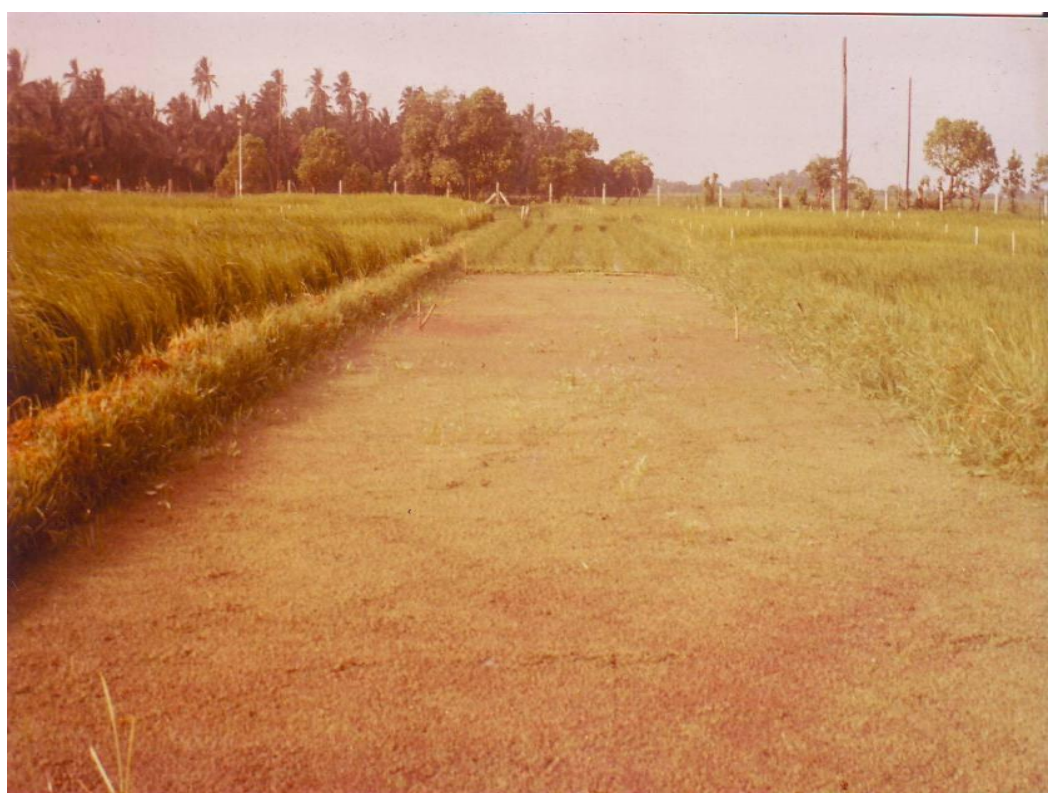

Figure 3. Growth of Azolla in a rice field at Ambalantota, Sri Lanka.

constraints for the adoption of this technology by the rice farmers are, handling of fresh bulky material, maintaining fresh cultures during the dry (fallow) periods, the need for frequent $\mathrm{P}$ fertilizer applications and the susceptibility of Azolla to pests and pathogens particularly under warm weather. It is therefore evident that the use of $\mathrm{N}_{2}$-fixing cyanobacteria and their symbiotic systems as biofertilizers for rice have only limited potential for widespread application.

\section{Toxigenic cyanobacteria}

Though cyanobacteria make positive contributions to global biodiversity and the environment particularly through carbon and nitrogen fixation they also cause severe problems in fresh water ecosystems and sewage treatment facilities by the production of toxins (Carmichael, 1994). It has already been mentioned that certain species form 'algal blooms' in polluted eutrophic waters (see section on Ecology and Distribution). Bloom forming species notably Microcystis, Anabaena, Aphanizomenon, Cylindrospermopsis and Nodularia frequently produce cyanobacterial toxins. Many such toxins have been initially named after some of these genera e.g. Microcystins from Microcystis, Anatoxins from Anabaena, Cylindrospermopsin from Cylindrospermopsis and Nodularin from Nodularia, although the production of such toxins is not confined to these genera but also produced by others. Toxins are not always produced and the mere presence of these genera should be considered only as a potential danger.
What factors trigger toxin production is not definitely known although it has been suggested to be a defense mechanism.

In mesotrophic, unpolluted waters the total algal populations are small but their diversity is high with almost equal representations from green algae, cyanobacteria (blue-green algae) and diatoms. When such a water body gets polluted and is subjected to high light and temperature, most of the eukaryotic algae tend to decline and a few blue-green algae (cyanobacteria) particularly those that produce toxins become dominant and sometimes form blooms. This has happened with the ancient irrigation reservoirs of Sri Lanka (Kulasooriya, 2004 and 2005a and b). Surveys conducted by Kulasooriya and others in collaboration with the National Water Supply and Drainage Board from late 1980 s to early 1990 s were communicated in several seminars and symposia (Kulasooriya, 1997 and 1998, Jayawardana et al., 1998 and Weerakoon et al., 1998) and the general public were made aware by newspaper articles (Kulasooriya, 2005b). Reports from Silva and Samarawickrama (2005) showed the presence of toxigenic cyanobacteria in the Kandy Lake and their dominance in most of the reservoirs of the Mahaweli river basin (Silva and Wijeyaratne, 1999). Jayatissa et al. (2006) in a comprehensive study covering 43 freshwater water bodies have shown that most of the irrigation tanks and reservoirs in Sri Lanka including the recent ones constructed under the Mahaweli project, have a predominance of toxin producing cyanobacteria except the reservoirs at 
Kalatuwawa and Labugama in which the catchment areas are under strict nature reserves. This is an indication that if pollution is minimized the occurrence of toxin producing cyanobacteria can be reduced. How such conditions can be established and sustained in irrigation tanks (reservoirs) would always remain a dilemma. Jayatissa et al. (2006) also reported for the first time the presence of microcystin LR toxin in some of the cyanobacterial samples collected in Sri Lanka. More recent studies have confirmed these results and it is now quite evident that a large number of inland freshwater bodies of Sri Lanka carry heavy populations of toxigenic cyanobacteria with Cylindrospermopsis being the dominant genus in a majority of them (Perera et al., 2011a, Perera et al., 2011b, Kulasooriya and Padmasiri, unpublished). The Institute of Fundamental Studies, Sri Lanka, now possesses facilities to detect and quantify cyanobacterial toxins in water samples. A number of samples collected from reservoirs and irrigation tanks from the dry zones of North Central and Wayamba Provinces have shown the presence of such toxins sometimes well over the levels permitted by WHO standards (Dr. D. N. Magana-Arachchi, IFS, personal communication). It is evident from these results that immediate steps should be taken to ameliorate the predominance of toxigenic cyanobacteria in water bodies of Sri Lanka, commencing from those used as sources for water supply schemes. It is also imperative to conduct well formulated scientific studies to verify the claims that toxigenic cyanobacteria are responsible for the prevalence and rapid increase of chronic kidney diseases of unknown etiology in certain areas of Sri Lanka.

\section{Some industrial applications}

Cyanobacteria are of common occurrence in waste water treatment plants. In some instances they have been found to be useful as low cost converters of odour causing and pollution creating dairy effluents into micro-algal biomass using sunlight (Lincoln et al., 1996). They were found to be very effective in removing $\mathrm{NH}_{4}$ ions and other nitrogen rich compounds from such effluents. In other cases toxigenic species have reduced the efficiency of waste water treatment plants (Martins et al., 2011). Toxins produced, particularly microcystins have not been antibacterial but they have adversely affected the protozoan populations. Nonetheless, other secondary metabolites of cyanobacteria have been found to be anti-bacterial and affected the decomposition rates of both aerobic and anaerobic bacteria.
On the other hand, cyanobacteria have been found to be useful in the bioremediation of industrial effluents and extraction of heavy metals. A number of species belonging to the genera of Synechococcus, Cyanothece, Oscillatoria, Nostoc and Nodularia isolated from pharmaceutical and textile industry effluents were demonstrated to be capable of biodegradation and biosorption of several heavy metals (Dubey et al., 2011). Using lyophilized Synechococcus sp. PCC 7942 immobilized in a silica polymer, Gardia-Torresday et al. (2011) demonstrated that this cyanobacterium could effectively bind $\mathrm{Cu}^{2+}, \mathrm{Pb}^{2+}, \mathrm{Ni}^{2+}, \mathrm{Cd}^{2+}, \mathrm{Cr}^{3+} \&$ $\mathrm{Cr}^{4+}$ and these metals could be recovered by elution with $0.1 \mathrm{M} \mathrm{HCl}$. It has even being reported that certain cyanobacteria can be useful in the cleaning of oil spills (Cohen, 2002). He tested species isolated from cyanobacterial mats developing in oil-contaminated sabkhas along the African coasts of the Gulf of Suez and in the pristine Solar Lake, Sinai. He found that axenic cultures of the isolated cyanobacteria by themselves are unable to degrade oil. In association with sulphate reducing and other heterotrophic bacteria from the mats, when exposed to light rapid degradation of oil was observed. The oxygenic photosynthesis of the cyanobacteria stimulated the aerobic decomposition by the associated bacteria. This shows the potential of producing cyanobacterial - eubacterial biofilms as efficient microbial consortia for cleaning of oil spills. Abed (2010) has reported the commencement of such a project in Oman.

Recently a few species of cyanobacteria have been investigated for biofuel production because their ability to convert solar energy to chemical energy has been found to be the most efficient among all living organisms. The efficiency of solar energy conversion in corn and sugarcane is $1-2 \%$, for eukaryotic algae it is around 5\% while for cyanobacteria it is $10 \%$. This can be understood if one looks at the photosynthetic pigments of cyanobacteria. In addition to chlorophyll-a these organisms contain phycobilisomes attached to the thylakoid membranes and these act as antennae in harvesting light for photosystem II. Among the pigments contained in the phycobilisomes, Phycoerythrin absorbs energy between the wave lengths of $500-600 \mathrm{~nm}$, Phycocyanin absorbs between $550-650 \mathrm{~nm}$ and Allophycocyanin absorbs between $600-675 \mathrm{~nm}$. Together with chlorophyll-a, their light absorption capacity will therefore extend right across the entire spectrum of visible light (Dr. Celia Smith, Department of Botany, University of Hawaii at Manoa, 
http://www. biologie.uni-hamburg.de/ b-online/ librarywebb/ BOT311/ Cyanobacteria). Furthermore, the simple genomic structure of these organisms has enabled gene sequencing and genetic engineering relatively easier. Professor James C. Liao of the University of California, Los Angeles, has inserted and spliced genes from other organisms to increase the $\mathrm{CO}_{2}$ fixing ability of Rubisco enzyme of Synechococcus elongatus. This transgenic strain produced isobutyraldehyde gas which could be recovered and converted to butanol. Prof. Malcolm R. Brown and Dr. David Nobles of the University of Texas, Austin have inserted a gene from Acetobacter xylinum to a cyanobacterium which could secrete alcohol and sugars. Prof. P. Fu and Dr. J. Dexter of the University of Hawaii have transformed Synechocystis strain PC 6803 by inserting pyruvate dehydrogenase and alcohol dehydrogenase II genes from Zymomonas mobilis to produce ethanol. The biggest break through has been reported by a private company Joule Technologies of Boston, Massachusetts, which has developed Bioreactors containing genetically modified cyanobacteria that could continuously secrete biofuel and ethanol (Lane, 2010). Reports on biofuel production capacities from different sources are given in Table 1.

Table 1. Production capacities of biofuel from different sources.

\begin{tabular}{lcc}
\hline Source & Gals/ac* & L/ha+ \\
\hline Soybean & 50 & 92 \\
Corn & 250 & 458 \\
Sugarcane & 450 & 825 \\
Oil palm & 650 & 1192 \\
Algae & 2000 & 3668 \\
Joule technologies & 15,000 & 27,512 \\
\hline \multicolumn{4}{l}{ Source: *Original report, + Converted }
\end{tabular}

The 15,000 gals/ac given by Dr. Dan Roberts, the principal scientist at Joule Technologies, eclipses all other claims. (Mail Online, Science \& Technology March 2, 2011).

It is interesting to note that in all these cases the most productive cyanobacteria have been unicellular species. This is perhaps due to their ability to harvest maximum solar energy per cell because the single cells turn and rotate with minimum self shading as they move up and down a bioreactor. Also their simple genomes permit easy genetic engineering compared to more complex counterpart resources. This opens a window of opportunity to conduct fundamental studies in Sri Lanka that could lead us to a commercially viable break through in biofuel production. Most of the other industrial platforms for biofuel production based upon feed stocks derived from higher plants require vast areas of cultivable land. For a small country like Sri Lanka it is a formidable task to allocate such extents of land without compromising on other more important economic uses. Algae based biofuels therefore appear to be an attractive option. Already unicellular cyanobacteria belonging to Synechococcus, Synechocystis, Chroococcidiopsis and Cyanothece have been isolated from different localities in Sri Lanka including brackish water and hot springs and partially sequenced (Wanigatunga et al., in preparation). With the commissioning of coal powered electricity generation systems sequestering $\mathrm{CO}_{2}$ emissions would be a major problem and such waste gases could be harnessed to grow biofuel cyanobacteria. Even the $\mathrm{CO}_{2}$ emitted by other industries like breweries and cement production factories can be used for algal cultivation.

\section{Cyanobacteria as a food supplement}

Among the vast array of cyanobacteria, two species have been used as food supplements of high nutritive value. They are Spirulina plantensis (syn. Arthrospira plantensis) and Aphanizomenon flos-aquae. These species have come from the traditional food habits of ancient civilizations of Aztecs, Mayans and Chinese and have been harvested from natural freshwater lakes such as Lake Chad in Africa, Upper Klamath in North America, Lake Texcoco in Mexico, and Lake Titicaca in Peru, South America. Currently they are also cultivated in large open raceway ponds with paddle wheel stirring under high $\mathrm{pH}$ and high temperature to minimize contamination by human pathogenic microorganisms. Such commercial production facilities are today found in the United States, Thailand, India, Taiwan, China, Pakistan, Myanmar and Chile. Spriulina is marketed as a source of complete nutrition which no other single organism can offer. Besides having a very high protein content ( $65-71 \%$ of dry weight) with all the essential amino acids, it is claimed to contain a wide spectrum of prophylactic and therapeutic nutrients including B-complex vitamins, minerals, proteins gamma linolenic acid and super antioxidants such as beta carotene, Vitamin E, trace elements and a number of unexplored bioactive compounds (Kulshreshtha et al., 2008). 
The other species, Aphanizomenon flosaquae as a food supplement (Carmichael et al., 2000) is wrought with the fear that certain species of Aphanizomenon produce toxins. It has been reported that colony forming species of Aphanizomenon do not produce toxins (Carmichael, 1994) and based upon 16s rRNA characteristics certain species have been misidentified (Li et al., 2003). However, reports of cylindrospermopsin producing species of Aphanizomenon flos-aquae have been reported from Germany (Preussela et al., 2006). Thus Food and Drug Administration Agencies as well as commercial enterprises that make Aphanizomenon based food supplements have a major responsibility to ensure that their products originate from non toxigenic species.

However, some of the claims of high nutritive value of these cyanobacterial products have been questioned. (Watanabe et al., 1999) who reported that Spirulina contains a 'psuedoVitamin B12' stated that it cannot replace the proper Vitamin B12 requirement, particularly in complete vegetarian diets. The general consensus of opinion appears to be that cyanobacterial based food supplements could provide a high level of nutrition particularly to poor sectors of the population who are malnourished, but they should not be considered as a replacement diet for animal protein sources such as fish, eggs, meat and milk.

Recently Spirulina has gained prominence for its therapeutic value against radiation, particularly after the disasters caused by the Chernobyl accident in Belarus, Russia and the tsunami damage to the Fukushima nuclear power plant in Japan. Citing several scientific papers published in the Journal of Applied Phycology Dr. Amha Belay, Vice President of Earthrise Farms in Irvine, California (a large scale Spirulina producing commercial venture) has posted review articles on the therapeutic value of this cyanobacterium particularly against effects of radiation (Belay, 2011).

The Institute of Fundamental Studies, Sri Lanka, has commenced a project in collaboration with the Mahatma Gandhi Center, Colombo, to introduce mass culture of Spirulina to villages in Sri Lanka as a low cost commercial activity to help alleviate poverty and reduce rural malnutrition Fig. 4 (a), (b) and (c).

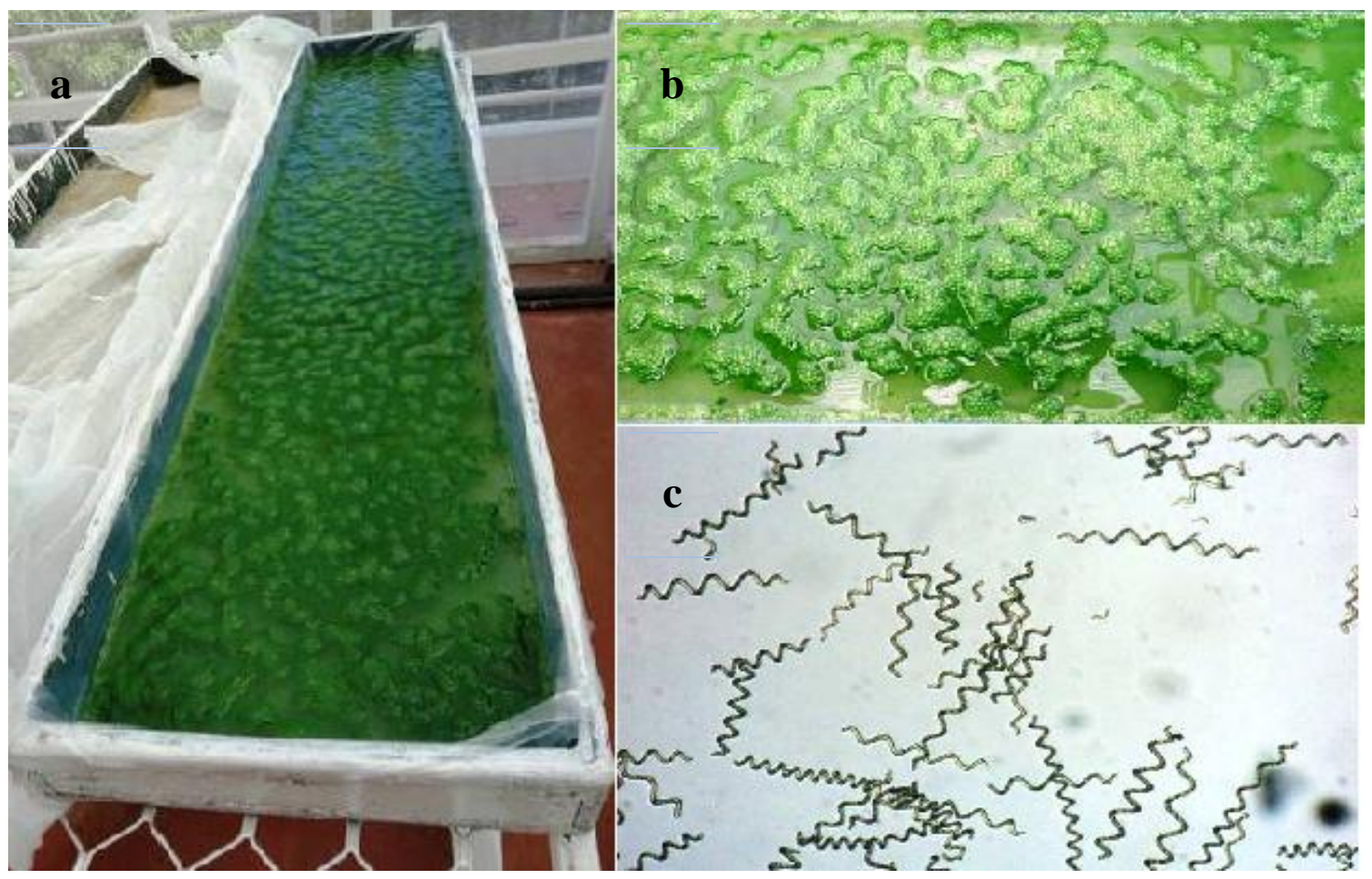

Figure 4. Spirulina cultures at the Institute of Fundamental Studies, Sri Lanka. (a) Open tray culture, (b) Close up of surface and (c) Microscopic view (x100). 


\section{CONCLUSION}

From the foregoing it is evident that although cyanobacteria are microscopic, prokaryotic organisms they are ubiquitous in their distribution and play crucial roles in the sustenance of many ecosystems. Their contributions to the global carbon and nitrogen bio-geochemical cycles are significant. These organisms also possess features that are useful as well as harmful to other living organisms including humans. Some of them appear to be good candidates for biofertilizer and biofuel industries and a few species are gaining recognition as highly nutritive food supplements as well therapeutic agents. Having knowledge about these little known microorganisms is therefore important and useful. If Planet Earth ever faced a global catastrophe resulting in colossal destruction of life, it is most likely that a few cyanobacterial species would survive in some extreme ecological niches and perhaps play a pioneering role in re-establishing life forms in a virtually barren Earth.

\section{REFERENCES}

Abed, Raed (2010). Oil bioremediation by cyanobacterial consortia under extreme environmental conditions. Oman Daily Sun (December).

Azolla Utilization (1987). Proceedings of the Workshop on Azolla Use, Fuzhou, Fujian, China 1985. The International Rice Research Institute, Los Banos, Philippines. Pp. 296.

Belay Amha (2011) The potential role of Spirulina in protection against radiation and its effects. http://www.iherb.com/i/info/ pic/Spirulina_RadiationA.pdf and http://www. earthrise.com/pdf/earthrisepdf.

Berman-Frank, I., Lundgren, P. and Fallwoski, P. (2003). Nitrogen fixation and photosynthetic oxygen evolution in Cyanobacteria (Mini review) Research in Microbiology 154: 157 - 164.

Capone, D. G., Zehr, J. P., Paerl, H. W., Bergman, B. and Carpenter, E. J. (1997). Trichodesmium, a globally significant marine cyanobacterium. Science 276 (May): 12211229.

Carmichael, W. W. (1994). The toxins of Cyanobacteria. Scientific American 270 (1): 78-86.

Carmichael, W. W., Li., R. And Pereira, P. (2000). Harvesting of Aphanizomenon flosaquae Ralfs ex Born. \& Flah.var. flos-aquae (cyanobacteria) from Klamath Lake for human dietary use. J. Appl. Phycol. 12: 585-595.

Carmichael, W. W., Azevedo, S. M., An, J. S., Molica, R. J., Jochimsen, E. M., Lau, S., Rinehart, K. L., Shaw, G. R. and Eaglesham, G. K. (2001). Human fatalities from cyanobacteria: chemical and biological evidence for cyanotoxins. Environ. Health Perspective 109 (7): 663 - 668.

Carpenter, E. J. and Romans, K. (1991). Major role of the cyanobacterium Trichodesmium in nutrient cycling in the North Atlantic Ocean. Science 254 (Nov): 1356 - 1358.

Cohen, Yehuda (2002). Bioremediation of oil by marine microbial mats. International Microbiology 5: 189 - 193.

Desikachary, T. V. (1959). Cyanophyta. Indian Council for Agricultural Research, New Delhi: 686p.

Drouet, F. (1968). Revision of the classification of the Oscillatoriaceae. Acad. Nat. Sci. Philadelphia, Monograph 15: p. 370.

Drouet, F. (1973). Revision of the Nostocaceae with cylindrical trichomes. Hafner Press, New York - London: 292p.

Drouet, F. (1977). Revision of the Nostocaceae with constricted trichomes. (beihefte Zur Nova Hedwigia, Heft 57), Publisher: Bisen Singh Mahendra Pal Singh (ISBN 812110503X and 9788211033): 258p.

Drouet, F and Daily, W. A. (1956). Revision of the coccoid Myxophyceae. Butler Univ. Bot. Stud. 12: 1218p.

Dubey, Sanjay Kumar, Dubey, Jaishree, Mehra, Sandeep, Tiwari, Pradeep and Bishwas A. J. (2011). Potential use of cyanobacterial species in bioremediation of industrial effluents. African Jour. Biotechnol. 10 (7): 1125 - 1132.

Fay, P. and Walsby, A. E. (1966). Metabolic activities of isolated heterocysts of the bluegreen alga Anabaena cylindrica. Nature 209: $810-812$.

Fay, P. and Kulasooriya, S. A. (1972). Tetrazolium reduction and nitrogenase activity in heterocystous blue-green algae. Arch. Mikrobiol. 87: 341 - 352.

Fogg, G. E., Stewart, W. D. P., Fay, P. and Walsby, A. E. (1973). The Blue-Green Algae, Academic Press, London \& New York: 459 Pp.

Friedmann, Imre E. (1982). Endolithic microorganisms in the Antarctic cold desert. Science 215 (4536): 1045 - 1053.

Friedmann, Imre E., Hua, Maosen and Friedmann, Roseli Ocampo (1988). Cryptoendolithic lichen and cyanobacteria communities of the Ross Desert, Antarctica. Polarforschung 58 (2/3): 251 - 259. 
Fritsch, F. E. (1942). The interrelations and classification of the Myxophyceae (Cyanophyceae). New Phytol. 41: 134 - 148.

Gallon, J. R., Hashem, M. A., and Chaplin, A. E. (1991). Nitrogen fixation by Oscillatoria $s p$. under autotrohic and photoheterotrophic conditions. Jour. Gen. Microbiol. 137: 31- 39.

Gardea-Torresday, J. L., Arenas J. L., Francisco, N. M. C., Tiemann, K. J. and Webb, R. (2011). Ability of immobilized cyanobacteria to remove metal ions from solution and demonstration of the presence of metallothionein genes in various strains. Jour. Hazardous Substance Res. 1: 2-18.

Geitler, L. (1932). Cyanophyceae. In: Kryptogamenflora von Deutschland, Osterreich und der Schweiz In: L. Rabenhorst (Ed.), Akademische Verlagsgesellschraft, Leipzig.14: $32-64$.

Janaki, S and Wolk, C. P. (1982). Synthesis of nitrogenase by isolated heterocysts. Biochim. Biophys. Acta. 696: $187-192$.

Jayatissa, L.P., Silva, E.I.L., McElhiney, J. and Lawton, L.A. (2006). Occurrence of toxigenic cyanobacterial blooms in freshwaters of Sri Lanka. Systematic and Applied Microbiology 29: $156-164$.

Jayawardana, B. P. A., Jayalath, J. M. J. C., Padmasiri, J. P. D. and Kulasooriya, S. A. (1998). Occurrence of potential toxin producing cyanobacteria in reservoirs of Sri Lanka. In: Symposium on Cyanobacterial Toxins in Water. Postgraduate Institute of Science, University of Peradeniya: Pp.7. (Abstract)

Johnson, I. Zackary, Zinser, Erik R., Coe, Allison, McNulty, Nathan P. E., Woodward, Malcolm S. and Chisholm, Sally M. (2006). Niche partitioning among Prochlorococcus ecotypes along ocean-scale environmental gradients. Science 311 (March): 1737 - 1740.

Karl, D., Letelier R., Tupas L., Dore J., Christian J. and Hebel D. (1997). The Role of Nitrogen Fixation in Bio-geochemical Cycling in the Sub-Tropical North Pacific Ocean. Nature 388: 533- 538 .

Komarek, J. (2006). Cyanobacterial Taxonomy: Current Problems and Prospects for the Inetgration of Traditional and Molecular Approaches. Algae 21 (4): 349 - 375.

Kulasooriya, S. A. (1997). Cyanobacteria and their toxins in water: Sri Lanka Country Report. In: Workshop on Cyanobacteria (Blue-Green Algae) and their toxins in water. July 1997, Brisbane, Queensland, Australia.

Kulasooriya, S. A. (1998). Freshwater cyanobacteria and their relevance to water supply in Sri Lanka. In: Symposium on
Cyanobacterial toxins in water. Postgraduate Institute of Science, University of Peradeniya: $8 \mathrm{Pp}$.

Kulasooriya, S. A. (2004). Ecology of Freshwater and Terrestrial Cyanobacteria (blue-green algae) of Sri Lanka. In. National Workshop on Current Status of Lower Plants in Sri Lanka. PGRC, Gannoruwa, Ministry of Environment \& Natural Resources, and the Royal Botanic Gardens.

Kulasooriya, S. A. (2005a). Potential toxin producing Cyanobacteria (blue-green algae) in water resources of Sri Lanka. In. Workshop on Hygiene Promotion \& Water Quality Surveillance for Water Board and Health Department Officials. PGRC, Gannoruwa, National Water Supply \& Drainage Board.

Kulasooriya, S. A. (2005b). Is the water we drink safe? Daily News (Monday 1stAugust): Pp.7 .

Kulasooriya, S. A. (2008). Biological Nitrogen Fixation: Fundamentals and Utilization. Science Education Unit, Faculty of Science, University of Peradeniya. Pp. 143.

Kulasooriya, S. A., Lang, N. J. and Fay, P. (1972). The heterocysts of blue-green algae. III Differentiation and nitrogenase activity. Proc. Roy. Soc. London, B 181: 199 - 209.

Kulasooriya, S. A., Roger, P. A., Barraquio, W. L. and Watanabe, I. (1981a). Epiphytic nitrogen fixation on weeds in a rice field ecosystem. In: Wetselaar, R. Simpson, J. R. \& Rosswall, T. (Eds.) Nitrogen Cycling in SouthEast Asian Wet Monsoonal Ecosystems, Australian Academy of Sciences, Canberra. Pp 56-61.

Kulasooriya, S. A., Roger, P. A., Barraquio, W. L. and Watanabe, I. (1981b). Epiphytic nitrogen fixation in deepwater rice. Soil Sci. Plant Nutr. 27: $19-27$.

Kulasooriya, S. A., Hirimburegama, W. K. and Abeysekera, S. W. (1987). Use of Azolla in Sri Lanka. In: Azolla Utilization, The International Rice Research Institute, Philippines Pp. 131 - 140.

Kulasooriya, S. A. and Hirimburegama, W. K. (1989). Phototrophic nitrogen fixation in wetland rice. In: Biological Nitrogen Fixation Associated with Rice Production (Eds) S. K. Dutta, \& C. Sloger, Oxford/IBH Publishers, New Delhi, Bombay \& Calcutta: Pp.191 210.

Kulshreshtha, Archana J., Ansih Z., Jarouliya, Urmila; Bhadauriya, Pratiksha; Prasad, G. B. K. S. and Bisen, P. S. (2008). Spirulina a wonder alga full of nutrition. Current Pharmaceutical Biotechnology 9 (5): 400 405. 
Lane, Jim (2010). Joule wins key patent for GMO cyanobacteria that creates fuel from sunlight, $\mathrm{CO}_{2}$ and water. Biofuels Digest 14 (September)

Lang, N. J. and Fay, P. (1971). The heterocysts of blue-green algae. II Ultrastructure. Proc. Roy. Soc. London, B 178: 193 -202.

Li, Renhuis, Carmichael, Wayne, W and Pereira, Paulo (2003). Morphological and 16S rRNA gene evidence for the re-classification of the para shellfish toxin producing Aphanizomenon flos-aquae LMCEYA 31 as Aphanizomenon issactschenkoi. Jour Applied Phycol. 39: 814 -818 .

Lincoln, E. P., Wilkie, A. C. and French, B. T. (1996). Cyanobacteria process for renovating dairy waste water. Biomass \& Bioenergy 10 (1): $63-68$.

Martins, Joana, Peixe, Luisa and Vasconselos, Vitor M. (2011). Unravelling cyanobacterial ecology in waste water treatment plants (WWTP). Microbial Ecology, 62 (2): 241 256.

Martin, W. and Kowallik, K. V. (1999). Annonated English translation of Mereschkowski's 1905 paper. Euro. Jou.r Phycol. 34 (3): 287 - 295.

Martin, W., Rujan, T., Richly, E., Hamen, A., Cornelsen, S., Lin, T., Leister, D., Stoebe, B., Hasegawa, M. and Penny, D. (2002). Evolutionary analysis of Arabidopsis, cyanobacteria and chloroplast genomes reveals plastid phylogeny and thousands of cyanobacterial genes in the nucleus. Proc. Natn. Acad. Sci., USA 99: 12246 - 12251.

Mereschkowsky, C. (1905). Uber Natur und Ursprung der Chromatophoren im Pflanzenreiche. Biol. Centrabl. 25: 593 - 604.

Mitsui, A., Kumazawa, A., Takahashi, A., Ikemoto, H., Cao, S. and Arai, T. (1986).

Strategy by which nitrogen-fixing unicellular cyanobacteria grow photoautotropically. Nature 323: 720 - 722 .

Mojzsis, S. J., Arrhenius, G., McKeegan, K. D., Harrison, Nutman A. P. and Friend, C. R. L. (1996). Evidence for life on Earth before 3,800 million years ago. Nature 384: 55 - 59 .

Murry, M. A., Horne, H. J. and Bennemann, J. R. (1984). Physiological studies of oxygen protective mechanisms in the heterocysts of Anabaena cylindrica. Appl. Environ. Microbiol. 47: 449 - 454.

Murry, M. A. and Wolk, C. P. (1989). Evidence that the barrier to the penetration of oxygen into the heterocysts depends upon two layers of the envelope. Arch. Mikrobiol. 151: $469-$ 474.
Nadis, Steve (2003). The cells that rule the seas. Scientific American (November): 52 - 57.

Olson, John M. ( 2006). Photosynthesis in the Archean Era. Photosynthesis Research 88: 109-17

Pearson, H. W., Marlin, G. and Howsley, R. (1981). Physiological studies on in vivo nitrogenase activity by axenic cultures of the blue-green alga Microcoleus chthnoplastes. British Phycol. Jour. 16: 139 Pp.

Perera Buddhika, Yatigammana Sudharma and Kulasooriya, S. A. (2011a). Diversity of plankton in some selected reservoirs in Sri Lanka. Proceedings International Symposium on Sustainable Use of Water: Challenges Ahead, Postgraduate Institute of Science, University of Peradeniya Pp.36 - 37.

Perera, M. B. U., Yatigammana, S. K., Kulasooriya, S. A. and Athukorala, N. P. (2011b). Cyanobacterial species composition and the limnology of the Padawiya Tank, during the dry season. Proceedings of Peradeniya University Sessions. Pp. 149.

Preussel, K., Stuken, A., Wiedner, C., Chorus, I and Fastner, J. (2006). First report on cylindrospermopsin producing Aphanizomenon flos-aqaue isolated from two German lakes. Toxicon 47 (2): 156 - 162.

Raven, J. A. and Allen, J. F. (2003) Genomics and Chloroplast evolution. What did cyanobacteria do for plants? Genome Biology 4: Pp 209.

Rippka, R., Deruelles, J., Waterbury, J. B., Herdman, M. and Stanier, R. Y. (1979). Genetic assignments, strain histories and properties of pure cultures of cyanobacteria. $J$. Gen. Microbiology 111: Pp.161.

Roger, P. A. and Kulasooriya, S. A. (1980). Blue- Green Algae and Rice. The International Rice Research Institute, Los Banos, Philippines Pp.113.

Roger, P. A., Kulasooriya, S. A., Barraquio, W. L. and Watanabe, I. (1981). Epiphytic nitrogen fixation on lowland rice plants. In: Wetselaar, R. Simpson, J. R. \& Rosswall, T. (Eds.) Nitrogen Cycling in South-East Asian Wet Monsoonal Ecosystems. Australian Academy of Sciences, Canberra. 62-66.

Silva, E.I.L. and Samaradiwakara, S.R.M.S. (2005). Limnology of Kandy Lake before the outbreak of a cyanobacterial bloom in May 1999.III. Phytoplankton composition and succession. Sri Lanka J. Aquatic Sci.10: 5571.

Silva, E. I. L. and Wijeyaratne, M. J. S. (1999). The occurrence of cyanobacteria in the reservoirs of the Mahaweli River Basin of Sri Lanka. Sri Lanka J. Aquatic Sci. 4: 51 - 60. 
Singh, R. N. (1961). Role of Nitrogen Fixing Blue-Green Algae. Indian Council for Agricultural Research, New Delhi: Pp175.

Smith Dr. Celia, Dept of Botany, University of Hawaii at Manoa, <http://www.biologie.unihamburg.de/bonline/librarywebb/BOT311/Cyanobacteria.>

Stanier, R. Y., Sistrom, W. R., Hansen, T. A., Whitton, B. A., Castenholz, R. W., Pfennig, N., Gorlenko, V. N., Kondratieva, E. N., Eimhjellen, K. E., Whittenbury, R., Gherna, R. N. and Truper, H. G. (1978). Proposal to place the nomenclature of the cyanobacteria (blue-green algae) under the rules of the International Code of Nomenclature of Bacteria. Int. J. Syst. Bacteriol. 28: 335 - 336.

Thomas, J. (1970). Absence of pigments of photosystem II of photosynthesis in heterocysts of a blue-green alga. Nature 228: $181-183$.

Venkataraman, G. S. (1972). Algal Biofertilizers and Rice Cultivation. Today and Tomorrows Printers and Publishers, Calcutta: Pp 81.

Wanigatunge Rasika Pabodani, MaganaArachchi Dhammika Nayoma, Chandrasekharan Naduwiladath, V. and Kulasooriya, S. A. (2011). Genetic diversity of cultured cyanobacterial isolates from Sri Lanka (in preparation)

Watanabe, F., Katsura, H., Takenaka, S., Fujita, T., Abe, K., Tamura, Y., Nakatsuka, T. and Nakano, Y. (1999). Pseudovitamin B (12) is the predominant cobamide of an algal health food, spirulina tablets. J. Agric. Food Chem. 47 (11): 4736-41

Watanabe, I., Ventura W., Cholitkul W., Roger P. A. and Kulasooriya, S. A. (1982). Potential of biological nitrogen fixation in deepwater rice. In: Proc. Deepwater Rice Workshop, The International Rice Research Institute, Los Banos, Philippines:.Pp 191 - 200.
Weerakoon, A. A., Jayawardana B. P. A., Padmasiri J. P. D. and Kulasooriya, S. A. (1998). Comparison of algal populations of Tisawewa and Basawakulama tanks in Anuradhapura. Symposium on Cyanobacterial Toxins in Water. Postgraduate Institute of Science, University of Peradeniya: Pp.11.

Weirzchos, Jacek., Ascaso, Carmen and Mackay, Christopher P. (2006). Endolithic cyanobacteria in halite rocks from the hyper arid core of the Atacama Desert. Astrobiology $6(3): 415-422$.

Wolk, C. P. (1970). Aspects of the development of a blue-green alga. Annals NY Acad. Sci. 175: $641-647$.

Wolk, C. P. and Wojciuch, C. (1971). Photo reduction of acetylene by heterocysts. Planta (Berlin) 97: 126 - 134.

Wolk, C. P (1982). Heterocysts. In: N. G. Carr and B. A. Whitton (Eds.), The Biology of Cyanobacteria. University of California, Berkeley, Press. Pp. 359 -386.

Wood, E. J. F. (1965). Marine Microbial Ecology, Chapman and Hall, London: 385p.

Yatigammana, S. K. (2004). Development and application of paleoecological approaches to study the impacts of anthropogenic activities on reservoirs in Sri Lanka. PhD. Thesis, Queens University, Kingston, Canada: Pp. 214.

Zehr, J. P., Wyman, M., Miller, V., Duguay, I. and Capone, D. G. (1993). Modification of the Fe-protein of nitrogenase in natural populations of Trichodesmium thiebautii. Appl. Environ. Microbiol. 59: 669 - 676. 